\title{
Comparison of Four MANOVA Test Statistic for Pig Production in Delta State, Nigeria
}

\author{
J. M. Aniesedo and C. N. Okoli
}

\begin{abstract}
This study used the multivariate analysis of variance (MANOVA) test statistic to examine the impact of three categories feed used in the production of pig in Delta State. The multivariate test statistic considered are the Pillai - Bartlett trace, Wilks' Test Statistic, Roy's Largest Root Test Statistic, and the Lawley- Hotelling (LH) Statistic. The objectives include to: evaluate the robustness of the four Multivariate Analysis of Variance test statistics to ensure that the best is employed in multivariate analysis to guarantee most useful result in pig production; determine the relatively efficient test statistic for pig production; and determine the test statistic that is consistent across the sample sizes. Secondary source of data collection was used to obtain the data required for the analysis. The outcome of the study showed that the obtained data was multivariate normally distributed based on the result of the asymmetrybased multivariate normality test and the multivariate normality test based on the kurtosis test which makes the data suitable parametric multivariate method such as multivariate analysis of variance (MANOVA). The results show that the Wilks and Roy tests found a significant difference for the intercept. While the Pillai and LH tests could not find any significance. The Roy test was also found to be significant for feed one, feed two, and feed three. The Wilks and Roy tests also turned out to be significant differences for the intercept. All test measures showed significance for feed one. The Wilks and Roy tests also showed a significant difference for feed two, while all test measures found a significance for feed one. Another result showed that none of the tests found significance for the interaction between feed one and two, while the Roy test found significance for the interaction between feed one and three, feed two and three and feed one, two and three. The performance of the test for evaluating the performance of feeds for pig production with/without considering interactions was found to be in the following order of magnitude: Roy, Wilks and Pilla = LH. This result implies that the Roy method, with or without consideration of the interaction, has a better performance of the test than the other methods considered in the study.
\end{abstract}

Index Terms - Feed, Multivariate Normality, MANOVA, Pig Production, Relative Efficiency.

\section{INTRODUCTION}

The statistical power is the probability of rejecting a false null hypothesis. Therefore, the meaningfulness of a statistic reflects the accuracy and probability with which it checks Type 1 errors. Thus, performance estimation is an important tool in the design of a study, but it is often ignored when designing multivariate studies because of the difficulties involved. Among the four statistics, there is not one particularly meaningful statistic: Hotelling- Lawley trace $\left(U^{(s)}\right)$, Pillai-Bartlett trace $\left(v^{(s)}\right)$, Wilk's likelihood ratio

Submitted on June 16, 2021.

Published on July 07, 2021.

J. N. Aniesedo, Delta State Polytechnic, Ozoro, Delta State, Nigeria.

(e-mail: aniesedojohnny@gmail.com)
( $\Lambda$ ) and Roy's Largest Root $(\theta)$, which are commonly used in multivariate analysis of variance (MANOVA). The performance fluctuates for a certain statistic and also for the four statistics, depending on whether there is a violation of the homogeneity of the covariance matrices or the multivariate normality and/or whether the non-centrality is concentrated or diffuse. Performance is also influenced by $\mathrm{p}$ value, sample size, and effect size.

The present study employed the MANOVA for assessing the performance of three pig production feed in Nigeria. The socio-economic benefits of farm animals cannot be overemphasized. Livestock provides people with useful goods and services in the form of animal by-products (such as meat, milk, hides and hides), traction and manure to improve soil fertility and serve as a reserve of capital that is available during difficult times. Among the animals used to alleviate animal protein deficiencies in humans, particularly in the rural areas of most developing countries in sub-Saharan Africa, is a pig [1]. The widespread adoption of pig production, especially among smallholders, could be due to its high survival rate and the ability to recycle a wide variety of agro-industrial by-products and crop residues with little or no processing and at a minimal cost. In addition, a pig is known to be a productive producer because it can produce 20 to 30 piglets per year and, if properly kept, can reach a slaughter weight of around 80 to $90 \mathrm{~kg}$ in around 7 to 9 months [2]. The availability of palm kernel cake courtesy of the NIPROC Company (a palm kernel processing company) has resulted in a spontaneous increase in pig production in the study area. Here pigs are raised in unconventional stalls such as parts of apartment buildings and incomplete apartment buildings without having to comply with the EPA (Environmental Protection Agency) regulation of 500 meters for apartment buildings.

Pigs have been described as one of the most productive and fastest-growing animals that can turn food waste into valuable products. They outperform other red meat animals such as cattle, sheep, and goats in converting feed into meat. And its annual growth rate $(3.8 \%)$ is higher than that of the human population $(2.30-2.80 \%)$. The native pigs have been recommended as a good alternative source of cheap, highquality animal protein suitable for the escalation of the human population. They have relatively low production costs and a rapid growth rate [3]. They also have a short production interval, high production potential, high productivity and high carcass yield. They easily adapt to environmental conditions. Pig production has therefore been advocated as a short-term

C. N. Okoli, Department of Statistics, Chukwuemeka Odumegwu Ojukwu University, Anambra State, Nigeria. 
measure to alleviate animal protein and calorie deficits, especially when no religious edicts are preventing their production and consumption. An estimated 4.4 million pigs live in Nigeria, about $78 \%$ of which are found in the subhumid zones of the savannah of northern and southern Guinea. Efforts have therefore been made to improve their productivity through adequate diet, improved health and management, and breed development specifically through crossing with superior exotic breeds. Not only is the pig a source of animal protein, but it also serves as an investment alternative and additional source of income, especially in rural areas. The size of the pig population in a particular region also depends on other factors, such as the climate; there are only a small number of pigs in the arid areas of the world and the social and religious beliefs of the indigenous people that pigs are few in countries with a predominantly Muslim population. The pig has some unique advantages over other animals that make it a good species to reproduce extensively to combat protein shortages. These advantages include their rapid growth rate, which is only marginally surpassed by the best, carefully managed broilers, their productivity which is unmatched by any other animal species except birds, their very good efficiency in feed conversion which brings better yields per unit of Inputs than most other animals and the quality of their meat, which is both tender and more nutritious in terms of protein and B vitamins than other animals. In the southern part of Nigeria, pig farming is kept in commercial quantities as there are no ethnic or religious taboos that prohibit their production. In most cases, however, it has been reported that pig farming is a secondary business and constitutes some proportion of the income of households, especially women.

The aim of the study is to employ the multivariate analysis of variance (MANOVA) test statistic for the assessment of feed used in the production of pig in Delta State with the following specific objectives:

i. To evaluate the robustness of the four Multivariate Analysis of Variance test statistics to ensure that the best is employed in multivariate analysis to guarantee most useful result in pig production.

ii. To determine the relatively efficient test statistic for pig production.

iii. To determine the test statistic that is consistent across the sample sizes.

\section{REVIEW OF RELATED LITERATURE}

The study Aminu and Akhigbe-Ahonkhai [4] examined the profitability and technical efficiency of pig production in the Nigerian state of Ekiti. A multi-stage sampling technique was used in the selection of 80 pig breeders. Primary data were collected from the selected pig breeders through a structured questionnaire. The data received from the farmers were analyzed using descriptive statistics, cost-benefit analysis and stochastic marginal production function. The results showed that the majority of the respondents were male, $40 \%$ were in the active age of 35 to 46 years who can effectively withstand the rigours and stresses of pig production, $76.25 \%$ were married and had an average household size of 6 people. The cost and income analysis showed that in one year of production the gross margin was 694,592. Fraud, while the return on investment was 0.34 and the cost-effectiveness ratio (CBR), was 1.34, indicating that the business is profitable as the CBR is higher. The result of the marginal stochastic production function gave that the herd size $(\mathrm{P}<0.05)$, the amount of feed $(\mathrm{P}<0.01)$, the capital $(\mathrm{P}<0.01)$ and the labour $(\mathrm{P}<0.05)$ increase the technical efficiency of the respondent's Age of respondents $(\mathrm{P}<0.1)$, level of education $(\mathrm{P}<0.01)$, household size $(\mathrm{P}<0.05)$, agricultural experience $(\mathrm{P}<0.01)$ and breed of pig $(\mathrm{P}<0.1)$ reared by the respondents. The mean technical efficiency was 0.86 . Although the pig farmers in the study area show high technical efficiency, the efficiency could be increased by $14 \%$ by better use of the available resources according to the current state of the art, which could be achieved by specific factors of the farmers such as age, education, and agricultural experience.

Ogunniyi and Omoteso [5] examined the profitability of pig production in the Ibadan metropolis in the state of Oyo. They obtained data for the study through an interview schedule given to 80 pig farmers in the area. The results of the study showed that $68.8 \%$ of the respondents were between 31 and 50 years old, with an average age of 41.4 years, less than $10 \%$ of the respondents had no formal education, 80 per cent were married, more than $70 \%$ more than 5 years of experience in pig farming, 98.8 per cent were Christians, the average invested capital was $15,187.80,000 \mathrm{~N}$, while $85 \%$ of those questioned financed their business from their savings. The results also showed that variable costs account for $93.5 \%$ while fixed costs account for $6.5 \%$ of total production costs. The average net agricultural income (NFI) per respondent was $\$ 81,470.81,000$ while the average net agricultural income per pig was $\mathrm{N} 1,198.10,000$. The return on investment was $57 \%$. The Cobb-Douglas production function showed that there was a significant correlation between the amount of pork produced in $\mathrm{kg}$ and the man-days employed, the amount of feed-in $\mathrm{kg}$ and the cost of drugs, disinfectants, and vaccines, while no significant correlation between total production and total production consists of years of experience and a level of the foundation. Based on the results, it is recommended that the government formulate and implement strategies that will increase productivity levels in the pig industry. These guidelines should include the enforcement of effective legislation to control feed quality and the subsidization of essential inputs such as feed, weaners and other equipment for pig production.

Ironkwe and Amefule [6] obtained the basic data on pig production and management in the state of Rivers. The study used a structural questionnaire given to 300 household pig farmers who were randomly selected from five communities in two Local Government Areas (LGAs) of Rivers State Nigeria. The data generated included socio-economic characteristics of the respondents and parameters for pig production. The data collected were analyzed by descriptive statistics such as mean standard deviation and percentages. The result showed that the influence of a socio-economic variable on pig production. Over $85 \%$ of respondents bought their basic stock from open markets, while some came from neighbours' herds. Grain, agro-industrial waste, and household waste were the main sources of animal feed. Awareness of the use of commercial feed was very low. The survey results showed that the main disease problems that respondents reported were helminthiasis, cough, diarrhoea, 
skin diseases, mainly sarcoptic mange and lice infestation. The number of weaned piglets/sow/year was highest in intensive piglets, followed by semi-intensive and extended piglets with the lowest number of piglets per year. Pig producers faced severe production constraints such as disease incidence, high feed costs, high costs of conventional medicines and poor housing. The need for and the means to improve pig production were highlighted.

Umeh et al. [7] examined the environmental impact of pig production in the Okigwe local government zone of Imo State, Nigeria. Their study aimed to describe the socioeconomic characteristics of the respondents; determination of the environmental impact of pig farming on the environment; Determination of the method of keeping pigs and the waste disposal methods of the respondents, determination of the factors that influence the choice of waste disposal methods by the respondents; and identify the restrictions on pig production waste management in the study area. As part of the study, 60 farmers were selected using targeted and multistage sampling procedures. The data were collected using a questionnaire and a secondary source. The data were analyzed using descriptive statistics such as percentage, frequency distribution table and the multinominal logit model. The results showed that most of the respondents were old, male, educated, and had large households. Moreover, in the pig farming method, the intensive method was the most popular. In addition, the open lagoon, landfill in the yard and storage in the sack were the main methods of waste disposal in pig farming. In addition, the result of the multinomial regression model for the choice of disposal methods showed that the age of the respondents, agricultural experience and membership in cooperative organizations was positive and significant. The main obstacles to pig waste management in the study area were poor access to credit, poor road network, water problem and high labour costs. Farmers' access to credit, a good road network and the availability of water must be ensured.

\section{MATERIAL AND METHODS}

This section discusses the four methods of power estimation in multivariate Analysis of variance. The concepts of evaluating the robustness of power of the methods are presented with a view to determining their relative robustness and the conditions under which any of them is uniformly most robust.

\section{A. Method of Data Collection}

The data for the study was secondary data collected from Akaramako Farm Oghara, Delta State, Nigeria. The data comprises weight of piglets from the period March 2020 September 2020

\section{B. Methods of Data Analysis}

In the multivariate case, we assume that $\mathrm{k}$ independent random sample of size $\mathrm{n}$ are obtained from a $\mathrm{p}$-variate normal populations with equal covariance matrices.

The totals and means are defined as follows:

Total of the $i_{\text {th }}$ sample: $y_{i .}=\sum_{i=1}^{n} y_{i j}$

Overall total:

$$
y_{. .}=\sum_{i=1}^{k} \sum_{j=1}^{n} y_{i j}
$$

Mean of the $i_{\text {th }}$ sample:

$\bar{y}_{i .}=\frac{y_{1}}{n}$

Overall mean:

$$
\bar{y}_{. .}=\frac{\mathrm{y}_{. .}}{\mathrm{kn}}
$$

For each observation vector in a multivariate one -way multivariate analysis of variance, we have the model:

$$
\begin{aligned}
& y_{i j}=\mu+\alpha_{i}+\epsilon_{i j} \\
& y_{i j}=\mu+\epsilon_{i j}, \mathrm{i}=1,2, \ldots, \mathrm{k} ; \mathrm{j}=1,2, \ldots, \mathrm{n}
\end{aligned}
$$

In terms of the $\mathrm{p}$ variables in $y_{i j}$ this deduces to:

$$
\left(\begin{array}{c}
y_{i j 1} \\
y_{i j 2} \\
\vdots \\
y_{i j p}
\end{array}\right)=\left(\begin{array}{c}
\mu_{1} \\
\mu_{2} \\
\vdots \\
\mu_{p}
\end{array}\right)+\left(\begin{array}{c}
\alpha_{i 1} \\
\alpha_{i 2} \\
\vdots \\
\alpha_{i p}
\end{array}\right)+\left(\begin{array}{c}
\epsilon_{i j 1} \\
\epsilon_{i j 2} \\
\vdots \\
\epsilon_{i j p}
\end{array}\right)=\left(\begin{array}{c}
\mu_{i 1} \\
\mu_{i 2} \\
\vdots \\
\mu_{i p}
\end{array}\right)+\left(\begin{array}{c}
\epsilon_{i j 1} \\
\epsilon_{i j 2} \\
\vdots \\
\epsilon_{i j p}
\end{array}\right)
$$

The model for the $\mathrm{r}^{\text {th }}$ variable $(r=1,2, \ldots, p)$ in each vector $\mathrm{y}_{\mathrm{ij}}$ is given by:

$$
y_{i j r}=\mu_{r}+\alpha_{i r}+\epsilon_{i j r}=\mu_{i r}+\epsilon_{i j r}
$$

We compare the mean vectors of the k-sample for significances differences. The hypothesis is now: $\mathrm{H}_{0}: \mu_{1}=\mu_{2}=\cdots=\mu_{k}$

versus

$\mathrm{H}_{1}$ : At least two $\mu$ 's is unequal. Equality of the mean vectors implies that the $\mathrm{k}$ means are equal for each variable; that is, $\mu_{1 r}=\mu_{2 r}=\ldots=\mu_{k r}$ for $\mathrm{r}=1,2, \ldots, \mathrm{P}$. If two means differ for just one variable, then $\mathrm{H}_{0}$ is false and we reject it. We can examine the element of the population mean vectors. 
$H_{0}=\left(\begin{array}{c}\mu_{11} \\ \mu_{12} \\ \vdots \\ \mu_{1 p}\end{array}\right)=\left(\begin{array}{c}\mu_{21} \\ \mu_{22} \\ \vdots \\ \mu_{2 p}\end{array}\right)=\cdots=\left(\begin{array}{c}\mu_{k 1} \\ \mu_{k 2} \\ \vdots \\ \mu_{k p}\end{array}\right)$

Thus $\mathrm{H}_{0}$ implies $\mathrm{P}$ sets of equalities:

$$
\begin{aligned}
& \mu_{11}=\mu_{21}=\cdots=\mu_{k 1} \\
& \mu_{12}=\mu_{22}=\cdots=\mu_{k 2} \\
& \vdots \\
& \mu_{1 p}=\mu_{2 p}=\cdots=\mu_{k p}
\end{aligned}
$$

All $\mathrm{P}(k-1)$ equalities must hold for $\mathrm{H}_{0}$ to true, failure of one equality will make the hypothesis false. In multivariate case, we have between and within matrices $\mathrm{H}$ and $\mathrm{E}$, defined as:

$$
\begin{aligned}
H & =n \sum_{i=1}^{k}\left(\overline{y_{i .}}-\overline{y_{. .}}\right)\left(\overline{y_{i .}}-\overline{y_{. .}}\right)^{\prime} \\
\mathrm{H} & =\sum_{i=1}^{k} \frac{1}{n} y_{i .} y_{i .}^{\prime}-\frac{1}{n k} y_{. .} y_{. .}^{\prime} \\
\mathrm{E} & =\sum_{i=1}^{k} \sum_{j=1}^{n}\left(y_{i j}-\overline{y_{i .}}\right)\left(y_{i j}-\overline{y_{i .}}\right)^{\prime} \\
\mathrm{E} & =\sum_{i j} y_{i j} y_{i j}^{\prime}-\sum_{i} \frac{1}{n} y_{i .} y_{i .}
\end{aligned}
$$

The $\mathrm{p} \mathrm{x}$ p hypothesis matrix $\mathrm{H}$ ha a between sun of square on the diagonal for each of the $p$ variable off-diagonal elements are equivalent sums of products for each pair of variables. Assuming there are no linear dependencies in the variables, the rank $H$ is the smaller of $p$ and $v_{H}, \min \left(p, v_{H}\right)$, where $v_{H}$ represents the degree of freedom for hypothesis; in these work we use one-way case $\mathrm{v}_{\mathrm{H}}=\mathrm{k}-1$. Thus, $\mathrm{H}$ can be singular. The $\mathrm{p} \times \mathrm{p}$ error matrix $\mathrm{E}$ has a within sum of squares for each variable on the diagonal with equivalent sums of products off-diagonal. The rank of $E$ is $p$, unless $v_{E}$ is less than $\mathrm{p}$.

Thus, $\mathrm{H}$ has the form of:

$$
H=\left(\begin{array}{cccc}
S S H_{11} & S P H_{12} & \cdots & S P H_{1 p} \\
S P H_{12} & S S H_{22} & \cdots & S P H_{2 p} \\
\vdots & \vdots & \ddots & \vdots \\
S P H_{1 p} & S P H_{2 p} & \cdots & S S H_{p p}
\end{array}\right)
$$

where

$$
S S H_{22}=n \sum_{i=1}^{k}\left(\bar{y}_{i .2}-\overline{y_{.2}}\right)^{2}=\sum_{i} \frac{y_{i .2}^{2}}{n}-\frac{y_{.2}^{2}}{k n}
$$

$$
\begin{aligned}
& S P H_{12}=n \sum_{i=1}^{k}\left(\bar{y}_{i .1}-\bar{y}_{. .2}\right)\left(\bar{y}_{i .2}-\bar{y}_{. .2}\right) \\
& =\sum \frac{y_{i .1} y_{i .2}}{n}-\frac{y_{. .1} y_{. .2}}{k n}
\end{aligned}
$$

In these expressions, the subscript 1 or 2 indicates the first or second variable. For example, $y_{i .2}^{-}$is the second element in $\overline{y_{i}}$.

$$
\overline{y_{i .}}=\left(\begin{array}{c}
- \\
y_{i .1} \\
\overline{y_{i .2}} \\
\vdots \\
\overline{y_{i . p}}
\end{array}\right)
$$

The matrix E can be expressed in a form similar to (11):

$$
E=\left(\begin{array}{cccc}
S S E_{11} & S P E_{12} & \cdots & S P E_{1 P} \\
S S P_{12} & S S E_{22} & \cdots & S P E_{2 P} \\
\vdots & \vdots & \ddots & \vdots \\
S P E_{1 P} & S P E_{2 P} & \cdots & S S E_{P P}
\end{array}\right)
$$

where,

$$
\begin{aligned}
& S S E_{22}=\sum_{i=1}^{k} \sum_{j=1}^{n}\left(y_{i j 2}-\overline{y_{i, 2}}\right)^{2}=\sum y_{i j 2}^{2}-\sum_{i} \frac{y_{i, 2}^{2}}{n} \\
& S P E_{12}=\sum_{i=1}^{k} \sum_{j=1}^{n}\left(y_{i j 1}-\overline{y_{i .1}}\right)\left(y_{i j 2}-\overline{y_{i .2}}\right) \\
& =\sum_{i j} y_{i j 1} y_{i j 2}-\sum_{i} \frac{y_{i, 1} y_{i, 2}}{n}
\end{aligned}
$$

The elements of E are sums of squares and products, not variances and covariance.

To estimate $\sum$, we use:

$$
S_{p 1}=\frac{E}{(n k-k)}
$$

$\sum=\left(\frac{\mathrm{E}}{n k-k}\right) \mathrm{E}$

\section{Power Estimation Methods}

There is no unique statistic; but, four statistics commonly used in MANOVA include Hotelling-Lawley trace $U^{(s)}$, the pillai-Bartlett trce $V^{(s)}$, the Wilk's like lihood $\operatorname{ratio}(\Lambda)$ and the Roy's largest Root $(\theta)$.

\section{The Pillai-Bartlett trace $\left(V^{(s)}\right)$}

They are two additional test statistics for \# $\mathrm{H}_{0}: \mu_{1}=\mu_{2}=\cdots=\mu_{k}$ based on the eigenvalues $\lambda_{1}, \lambda_{2}, \cdots, \lambda_{s}$ of $\mathrm{E}^{-1} \mathrm{H}$ 
$V^{(s)}=\operatorname{tr}\left[(E+H)^{-1} H\right]=\sum_{i=1}^{s} \frac{\lambda_{i}}{1+\lambda_{i}}$

We reject $\mathrm{H}_{0}$ for $V^{(s)} \geq V_{\alpha}^{(s)}$.

The parameters: $\mathrm{s}, \mathrm{m}$, and $\mathrm{N}$ are defined as:

$s=\min \left(V_{H}, P\right), m=\frac{1}{2}\left(\left|V_{H}-P\right|-1\right), N=\frac{1}{2}\left(V_{\mathrm{E}}-P-1\right)$

where:

$\mathrm{P}=$ number of variables;

$\mathrm{V}_{\mathrm{H}}=$ degree of freedom of hypothesis;

$\mathrm{V}_{\mathrm{E}}=$ degree of freedom for error.

Pillai's test statistic in (18) is an extension of Roy's statistic. If the mean vector does not lie in one dimension. The $\mathrm{F}$ approximation for Pillai $\mathrm{V}^{(\mathrm{s})} \mathrm{F}$-statistic,

$F_{1}=\frac{(2 N+s+1) V^{(s)}}{(2 m+s+1)\left(s-V^{(s)}\right)}$

which is approximately distributed as $\mathrm{F}_{\mathrm{s}(2 \mathrm{~m}+\mathrm{s}+1, \mathrm{~s}(\mathrm{~N}+\mathrm{s}+1))}$. The two alternative $\mathrm{F}$ - approximation is given by:

$F_{2}=\frac{s\left(v_{\mathrm{E}}-v_{\mathrm{H}}+s\right) V^{(s)}}{p v_{H}\left(s-V^{(s)}\right)}$

With $p v_{H}$ and $s\left(v_{\mathrm{E}}-v_{H}+s\right)$ degree of freedom and

$F_{3}=\frac{\left(v_{E}-p+s\right) V^{(s)}}{d\left(s-V^{(s)}\right)}$

With sd and V degree of freedom, where $d=\max \left(p, v_{E}\right)$. Also, $F_{3}$ and $F_{1}$ are the same.

\section{E. The Lawley- Hotelling Statistic}

$U^{(s)}=\operatorname{tr}\left(\mathrm{E}^{-1} H\right)$

And is known as Hotelling's generalized $\mathrm{T}^{2}-$ statistics that gives the upper points of the test statistic as:

$\frac{v_{E}}{v_{H}} U^{(s)}$

We reject $\mathrm{H}_{0}$ for large values of the test statistic, $p \leq v_{H}$ and $p \leq v_{E}$. If $p>v_{H}$, use $\left(v_{H}, p, v_{E}+v_{H}-p\right)$ in place of $\left(p, v_{H}, v_{E}\right)$. If $v_{H}=1$ and $p>1$, use the relationship $\mathrm{U}^{(1)}=$ $\mathrm{T}^{2} / \mathrm{v}_{\mathrm{E}}$.

The approximation of $\mathrm{F}$ - statistic for Lawley $\mathrm{U}^{(\mathrm{s})}$.

$F_{1}=\frac{U^{(s)}}{c}$ which is distributed as $F_{a, b}$,

where

$a=p v_{H}$,

$b=4+\frac{a+2}{B-1}$,

$c=\frac{a(b-2)}{b\left(v_{E}-p-1\right)}$,

$B=\frac{\left(v_{E}+v_{H}-p-1\right)\left(v_{E}-1\right)}{\left(v_{E}-p-3\right)\left(v_{E}-p\right)}$

\section{Wilks' Test Statistic A}

The likelihood ratio test of $H_{0}: \mu_{1}=\mu_{2}=\cdots=\mu_{k}$ is given by

$\Lambda=\frac{|E|}{|E+H|}$

This is known as Wilks' $\Lambda$. We reject $\mathrm{H}_{0}$ if $\Lambda \leq \Lambda_{\alpha, p, v_{H}, v_{E}}$.

\section{Roy's Largest Root Test Statistic}

To test $H_{0}: \mu_{1}=\mu_{2} \cdots=\mu_{k}$ based on $\lambda_{1}$, we use the Roy's union -intersection test called the Roy's largest root test. The statistic is given by:

$\theta=\frac{\lambda_{1}}{1+\lambda_{1}}$

We reject $\mathrm{H}_{0}: \mu_{1}=\mu_{2}=\ldots=\mu_{\mathrm{k}}$ if $\theta \geq \theta_{\alpha, \mathrm{s}, \mathrm{m}, \mathrm{N}}$. The parameters $\mathrm{s}$, $\mathrm{m}$, and $\mathrm{N}$ are defined as follows $\mathrm{s}=\min \left(\mathrm{v}_{\mathrm{H}}, \mathrm{p}\right)$, $m=\frac{1}{2}\left(\left|v_{H}-p\right|-1\right)$ and $N=\frac{1}{2}\left(v_{E}-p-1\right)$ Related software programs provide upper bound $\mathrm{F}$ - approximation formulas given by:

$F=\frac{\left(v_{E}-d-1\right) \lambda_{1}}{d}$

With degrees of freedom $d$ and $v_{E}-d-1$, where $d=\max \left(p, v_{H}\right)$. The term upper bound indicates that the $\mathrm{F}$ in the above equation is greater the true $\mathrm{F}^{\prime \prime}$; that is $F>F_{d, v_{E}-d-1}$. Therefore, we feel safe when we accept $\mathrm{H}_{0}$, but if we reject $\mathrm{H}_{0}$ it indicates that the information is baseless.

\section{DATA ANALYSIS AND RESULTS}

This section discusses the data analysis for the work, presentation of result obtained and interpretation of the result.

\section{A. Multivariate Normality Test of the Performance of the Pig Feeds}

TABLE I: Multivariate NORMALITY TEST BASED ON SKEWNESS FOR PERFORMANCE OF PIG FEEDS 


\begin{tabular}{ccccc}
\hline Feeds & $\begin{array}{c}\text { U test } \\
\text { value }\end{array}$ & Df & p-value & Remark \\
\hline Feed_one & 0.26 & 2 & 0.8781 & $\begin{array}{c}\text { Multivariate } \\
\text { Normal } \\
\text { Multivariate } \\
\text { Normal } \\
\text { Fultivariate } \\
\text { normal }\end{array}$ \\
\hline
\end{tabular}

The result of the asymmetry-based multivariate normality test presented in table 1 showed that the data is multivariate normally distributed with U-values of $0.26,2.7855$, and 1.3030 for feed one, feed two and feed three respectively with the corresponding $\mathrm{p}$-values found to be greater than the critical value of 0.05 (p-value $=0.8781,0.2484$, and 0.4981 > $\alpha=0.05$ ).

TABLE II: MULTIVARIATE NORMALITY TEST BASED ON KURTOSIS FOR PERFORMANCE OF THE PIG FEEDS

\begin{tabular}{|c|c|c|c|c|c|c|c|}
\hline Feeds & $\begin{array}{l}\text { W test } \\
\text { Value }\end{array}$ & df1 & df2 & w1 & w2 & $\begin{array}{c}\mathrm{P} \\
\text {-value }\end{array}$ & Remark \\
\hline $\begin{array}{l}\text { Feed } \\
\text { one }\end{array}$ & 5.356 & 1.5 & 2.0 & 2.0 & 1.0 & 0.3578 & $\begin{array}{c}\text { Multivariate } \\
\text { normal }\end{array}$ \\
\hline $\begin{array}{l}\text { Feed } \\
\text { two }\end{array}$ & 7.074 & 1.5 & 2.0 & 2.0 & 1.0 & 0.2348 & $\begin{array}{c}\text { Multivariate } \\
\text { normal }\end{array}$ \\
\hline $\begin{array}{l}\text { Feed } \\
\text { three }\end{array}$ & 5.843 & 1.5 & 2.0 & 2.0 & 1.0 & 0.3181 & $\begin{array}{c}\text { Multivariate } \\
\text { norm }\end{array}$ \\
\hline
\end{tabular}

The result of the multivariate normality test based kurtosis presented in Table II showed that the data multivariate normally distributed with $\mathrm{W}$ values of 5.3. 7.0748, and 5.8439 for feed one, feed two and feed th respectively with corresponding $\mathrm{p}$-values which was founc be greater than the significant value of 0.05 (p-value $=0.35$ 0.2348 , and $0.3181>\alpha=0.05$ ). Hence, the data satisfy required assumption to apply a parametric multivari method such as the multivariate analysis of varias (MANOVA).

The Table III presents the performance of the three ty] of Pig feed using MANOVA without considerj interactions.

TABLE III: RESUlt OF MULTIVARIATE ANALYSIS FOR THREE DIFFERE DIET ON PERFORMANCE OF PIG WITHOUT INTERACTION

\begin{tabular}{|c|c|c|c|c|c|}
\hline Parameters & Statistics & Pillai & Wilks & $\mathrm{HL}$ & Roy \\
\hline \multirow{4}{*}{ Intercept } & $\begin{array}{c}\text { Test } \\
\text { value }\end{array}$ & -15.5 & 247.8 & -15.5 & $509.0=$ \\
\hline & Num DF & 3 & 3 & 3 & 3 \\
\hline & Den DF & 31 & 31 & 31 & 31 \\
\hline & $\begin{array}{l}\text { Sig. } \\
\text { value }\end{array}$ & 0.0 & 0.000 & 0.1670 & 0.000 \\
\hline \multirow{4}{*}{ Feed_one } & $\begin{array}{c}\text { Test } \\
\text { value }\end{array}$ & -32.0 & 0.01 & -32.0 & $691.0 \varepsilon$ \\
\hline & Num DF & 6 & 6 & 6 & 3 \\
\hline & Den DF & 64 & 62 & 64 & 32 \\
\hline & $\begin{array}{l}\text { Sig. } \\
\text { value }\end{array}$ & 1.00 & 0.9999 & 1.000 & 0.000 \\
\hline \multirow{4}{*}{ Feed_two } & $\begin{array}{c}\text { Test } \\
\text { value }\end{array}$ & -32.0 & 0.01 & -32.0 & $370.4 c$ \\
\hline & Num DF & 6 & 6 & 6 & 3 \\
\hline & Den DF & 64 & 62 & 64 & 32 \\
\hline & $\begin{array}{l}\text { Sig. } \\
\text { value }\end{array}$ & 1.00 & 0.9999 & 1.00 & 0.000 \\
\hline \multirow{4}{*}{ Feed_three } & $\begin{array}{c}\text { Test } \\
\text { value }\end{array}$ & -32.0 & -0.0028 & -32.0 & 235.7 \\
\hline & Num DF & 6 & 6 & 6 & 3 \\
\hline & Den DF & 64 & 62 & 64 & 32 \\
\hline & $\begin{array}{l}\text { Sig. } \\
\text { value }\end{array}$ & 1.000 & 0.999 & 1.00 & 0.000 \\
\hline
\end{tabular}

The findings show in Table IV that the Wilks and the Roy test found a significant difference for the intercept with test values of 0.001 ( $\mathrm{p}$-value $=0.00<0.05$ ) and 220.82 (pvalue $=0.00<0.05)$ respectively. All the test measures found significance for Feed one with test values of 3 (p-value $=0<$ $0.05), 0.001(\mathrm{p}$-value $=0.00<0.05), 3(\mathrm{p}$-value $=0<0.05)$ and 143.69 (p-value $=0.00<0.05)$ respectively. Also, the Wilks and the Roy test found a significant difference for Feed two with test values of 0.001 (p-value $=0.00<0.05$ ) and 619.89 ( $\mathrm{p}$-value $=0.00<0.05)$ respectively while all the test measures found significance for Feed one with test values of 2 (p-value $=0<0.05), 0.001(\mathrm{p}$-value $=0.00<0.05), 2(\mathrm{p}$-value $=0<$ 0.05 ) and 619.89 (p-value $=0.00<0.05$ ) respectively. Further result showed that none of the test found significance for the interaction between feed one and two while the Roy test was able to find significance for the interaction between feed one and three, feed two and three and feed one, two and three with the test values of 1 (p-value $=0.0305<0.05), 1(\mathrm{p}$-value $=$ $0.0430<0.05$ ), and 2 ( $\mathrm{p}$-value $=0.0296<0.05$ ), respectively. Also, table 4 shows the performance of the three types of Pig feed using MANOVA with interactions.

TABLE IV: RESUlt OF MUlTIVARIATE ANALYSIS FOR THREE DIFFERENT DIET ON PERFORMANCE OF PIG WITH INTERACTION

\begin{tabular}{|c|c|c|c|c|c|}
\hline Parameters & Statistics & Pillai & Wilks & $\mathrm{HL}$ & Roy \\
\hline \multirow{4}{*}{ Intercept } & $\begin{array}{c}\text { Test } \\
\text { value }\end{array}$ & 3.0 & 0.0001 & 3.0 & 220.82 \\
\hline & Num DF & 3 & 3 & 3 & 3 \\
\hline & Den DF & 11 & 11 & 11 & 11 \\
\hline & Sig. value & 0.16 & 0.000 & 0.16 & 0.000 \\
\hline \multirow{4}{*}{ Feed_one } & $\begin{array}{c}\text { Test } \\
\text { value }\end{array}$ & 3 & 0.0001 & 3 & 143.69 \\
\hline & Num DF & 6 & 6 & 6 & 3 \\
\hline & Den DF & 64 & 22 & 64 & 12 \\
\hline & Sig. value & 0.00 & 0.000 & 0.000 & 0.000 \\
\hline \multirow{4}{*}{ Feed_two } & $\begin{array}{l}\text { Test } \\
\text { value }\end{array}$ & 3 & 0.0001 & 3 & 619.89 \\
\hline & Num DF & 6 & 6 & 6 & 3 \\
\hline & Den DF & 64 & 22 & 64 & 12 \\
\hline & Sig. value & 0.0122 & 0.000 & 0.0122 & 0.000 \\
\hline \multirow{4}{*}{ Feed_three } & $\begin{array}{c}\text { Test } \\
\text { value }\end{array}$ & 2 & 0.0001 & 2 & 619.89 \\
\hline & Num DF & 6 & 6 & 6 & 3 \\
\hline & Den DF & 64 & 22 & 64 & 12 \\
\hline & Sig. value & 0.000 & 0.000 & 0.000 & 0.000 \\
\hline \multirow{4}{*}{ d_one:Feed_two } & $\begin{array}{l}\text { Test } \\
\text { value }\end{array}$ & 0.3973 & 0.6401 & 0.3973 & 0.0001 \\
\hline & Num DF & 12 & 12 & 12 & 4 \\
\hline & Den DF & 39 & 29 & 39 & 13 \\
\hline & Sig. value & 0.9044 & 0.9277 & 0.9044 & 0.37864 \\
\hline \multirow{4}{*}{ d_one:Feed_three } & $\begin{array}{l}\text { Test } \\
\text { value }\end{array}$ & 3.00 & 0.30508 & 3.00 & 1.000 \\
\hline & Num DF & 12 & 12 & 12 & 4 \\
\hline & Den DF & 39 & 29 & 39 & 13 \\
\hline & Sig. value & 0.2107 & 0.2268 & 0.2107 & 0.03051 \\
\hline \multirow{4}{*}{ d_two:Feed_three } & $\begin{array}{c}\text { Test } \\
\text { value }\end{array}$ & 0.8991 & 0.26466 & 0.8991 & 1.000 \\
\hline & Num DF & 12 & 12 & 12 & 4 \\
\hline & Den DF & 39 & 29 & 3939 & 13 \\
\hline & Sig. value & 0.1149 & 0.1462 & 0.1149 & 0.04302 \\
\hline \multirow{4}{*}{ :Feed_two:Feed_three } & $\begin{array}{c}\text { Test } \\
\text { value }\end{array}$ & 1.014 & 0.1178 & 1.014 & 2.000 \\
\hline & Num DF & 24 & 24 & 24 & 8 \\
\hline & Den DF & 39 & 39 & 39 & 13 \\
\hline & Sig. value & 0.1408 & 0.1490 & 0.1408 & 0.02960 \\
\hline
\end{tabular}

The findings show in Table IV that the Wilks and the Roy test found a significant difference for the intercept with test values of 0.001 (p-value $=0.00<0.05)$ and $220.82(p-$ value $=0.00<0.05)$, respectively. All the test measures found significance for Feed one with test values of 3 (p-value $=0<$ 
$0.05), 0.001(\mathrm{p}$-value $=0.00<0.05), 3(\mathrm{p}$-value $=0<0.05)$ and 143.69 (p-value $=0.00<0.05$ ), respectively. Also, the Wilks and the Roy test found a significant difference for Feed two with test values of $0.001(p$-value $=0.00<0.05)$ and 619.89 $(\mathrm{p}$-value $=0.00<0.05)$ respectively while all the test measures found significance for Feed one with test values of 2 ( $p$-value $=0<0.05), 0.001(\mathrm{p}$-value $=0.00<0.05), 2(\mathrm{p}$-value $=0<$ $0.05)$ and 619.89 (p-value $=0.00<0.05)$, respectively. Further result showed that none of the test found significance for the interaction between feed one and two while the Roy test was able to find significance for the interaction between feed one and three, feed two and three and feed one, two and three with the test values of 1 (p-value $=0.0305<0.05), 1(\mathrm{p}$-value $=$ $0.0430<0.05)$, and 2 (p-value $=0.0296<0.05)$, respectively. The table 5 presents the average performance of the three types of Pig feed without considering interactions.

TABLE V: RESUlt OF AVERAGE PERFORMANCE OF PIG WITHOUT INTERACTION

\begin{tabular}{ccccc}
\hline Statistics & Pillai & Wilks & HL & Roy \\
\hline Test value & -27.875 & 61.9543 & -27.875 & 451.575 \\
Num DF & 5.25 & 5.25 & 5.25 & 3 \\
Den DF & 55.75 & 54.25 & 55.75 & 31.75 \\
Sig. value & 0.79175 & 0.749925 & 0.79175 & 0 \\
Power & 0.7853 & 0.7905 & 0.7853 & 0.8340 \\
\hline
\end{tabular}

The result obtained in Table $\mathrm{V}$ showed that the power of the test for assessing the performance of the feeds for pig production without the consideration of interactions is in the following order of magnitude Roy (power=83.40\%), Wilks $($ power $=79.05 \%)$, and Pilla $($ power $78.53 \%)=$ HL $($ power $78.53 \%$ ). This result implies that the Roy method has the better power of the test without the consideration of interaction than the other methods considered in the study.

The Table VI presents the average performance of the three types of Pig feed with interactions.

TABLE VI6: Result of AVERAGe PERformanCE OF PIG WITH

\begin{tabular}{ccccc}
\multicolumn{5}{c}{ INTERACTION } \\
\hline Statistics & Pillai & Wilks & HL & Roy \\
\hline Test value & 2.0388 & 0.166005 & 2.0388 & 201.0363 \\
Num DF & 10.125 & 10.125 & 10.125 & 4 \\
Den DF & 44.875 & 25.375 & 45.714 & 12.375 \\
Sig. value & 0.1938 & 0.1812 & 0.1975 & 0.0602 \\
Power & 0.8608 & 0.9034 & 0.8608 & 0.9158 \\
\hline
\end{tabular}

\section{CONCLUSION}

From the outcome of the whole study, the following conclusions are drawn from both the preliminary results and the power analysis result it was found that; on the basis of the result of the asymmetry-based multivariate normality test and the multivariate normality test based on the kurtosis test that the data were multivariate normally distributed and meet the required assumption to apply a parametric multivariate method such as multivariate analysis of variance (MANOVA). The results show that the Wilks and Roy tests found a significant difference for the intercept. While the Pillai and HL tests could not find any significance. The Roy test was also found to be significant for feed one, feed two, and feed three. The Wilks and Roy tests also turned out to be significant differences for the intercept. All test measures showed significance for feed one. The Wilks and Roy tests also showed a significant difference for feed two, while all test measures found a significance for feed one. Another result showed that none of the tests found significance for the interaction between feed one and two, while the Roy test found significance for the interaction between feed one and three, feed two and three and feed one, two and three.

The performance of the test for evaluating the performance of feeds for pig production with/without considering interactions was found to be in the following order of magnitude: Roy, Wilks and Pilla $=$ HL. This result implies that the Roy method, with or without consideration of the interaction, has a better performance of the test than the other methods considered in the study. Having concluded the analysis of this research, the following recommendations are stated; future studies should carry out a similar work with other multivariate approaches such as the Profile analysis for the assessment of performance of pig production in various parts of Nigeria.

\section{REFERENCES}

[1] O. O. Tewe, M. W. Ogrodgo, and, A.O.K. Adesehinwa, "Resources requirements for profitability pig farming in Nigeria', In: National. Pig prod. Training Manual, NAERLS/ABU, 2009, Pp 16-26.

[2] G. John, "Modern pig production technology", Nottingham: Nottinghom University of Press, 2011. Pp. 137-139.

[3] O.M. Osaro, Enhancing production performance of small holder pig farming. In: Oyedokun A.O and Adeshinwa (Eds) Pig production Workshop Training Manual, N.A.E.R.L.S/A.B.U. Zaria Nigeria, 1995, pp. $100-130$.

[4] F. O. Aminu and C. E. Akhigbe-Ahonkhai, "Profitability and Technical Efficiency of Pig Production in Nigeria: The Case of Ekiti State", Agricultura Tropica Et Subtropica, 2017, 50/1, 27-35. DOI: 10.1515/ats-2017-0004.

[5] L. T. Ogunniyi and O. A. Omoteso, "Economic Analysis of Swine Production in Nigeria: A Case Study of Ibadan Zone of Oyo State". J. Hum. Ecol., 2011, 35(2): 137-142.

[6] Ironkwe, M.O. and Amefule, K. U. (2008). Appraisal of Indigenous Pig Production and Management Practices In Rivers State, Nigeria. Journal of Agriculture and Social Research (JASR), 8(1): 1-7.

[7] S. I. Ume, C. I. Ezeano and B. O. Gbughemobi, "Analysis of the Environmental Effect of Pig Production in Okigwe Local Government Area of Imo State, Nigeria". International Journal of Environmental \& Agriculture Research (IJOEAR), 2018, 4(6): 12-21. 